\title{
TRATAMENTO DE EFLUENTE DE FECULARIA POR COAGULAÇÃO/ FLOCULAÇÃO
}

\author{
J. D. SANTOS ${ }^{1 *}$, M. V. VEIT ${ }^{2}$, J. C. ZANETTE ${ }^{3}$, G. da C. GONÇALVES ${ }^{4}$, M. R. F. KLEN ${ }^{5}$, K. C. \\ $\mathrm{KERBER}^{6}$
}

1- Universidade Estadual do Oeste do Paraná, Campus Toledo/Mestranda-Engenharia Química -

2, 5,- Universidade Estadual do Oeste do Paraná, Campus Toledo, Docente Departamento de Engenharia Química

3, 6- Universidade Estadual do Oeste do Paraná, Campus Toledo. Graduando em Engenharia

Química.

4- Universidade Tecnológica Federal do Paraná, Campus Toledo.

*jordanadorca@gmail.com

\begin{abstract}
RESUMO
O processo de industrialização da mandioca gera um efluente vulgarmente chamado de manipueira, que apresenta alta carga orgânica e cianeto livre (HCN) altamente tóxico para biota e em altas concentrações para o ser humano. Este trabalho estudou o tempo de sedimentação de um efluente da indústria de produção de fécula de mandioca pelo processo de coagulação/floculação e comparou a eficiência de remoção de cor e turbidez para dois coagulantes. As amostras de efluentes foram coletadas em uma fecularia da região oeste do Paraná e caracterizado conforme metodologias (APHA, 1998). Foram variadas as concentrações dos coagulantes de 15 até $75 \mathrm{mg} \mathrm{L}^{-1}$ dos coagulantes Acquapol WW e Sulfato de Alumínio, analisando cor, turbidez e pH. O experimento de coagulação/floculação utilizou equipamento Jart-test analógico, fixando o Tempo de Mistura Rápida, Tempo de Mistura Lenta). Obteve-se um tempo mínimo de sedimentação igual a 10 min e verificou-se que o coagulante natural $(87,71 \%$ de turbidez e 50,71\% de cor) assim apresentando uma eficiência de remoção de cor e turbidez muito superior ao sulfato de alumínio (38,7\% de turbidez e $26,39 \%$ de cor) na menor concentração.
\end{abstract}

\section{INTRODUÇÃO}

A produção de fécula de mandioca tem grande importância econômica para o setor alimentício e também como fonte de renda e emprego para várias regiões do Brasil. O principal resíduo do processo é a água de lavagem ou manipueira que possui alta carga orgânica, elevada turbidez e compostos tóxicos como glicosídeos cianogênicos e linamarina. (BRSCAN, 2011; LAMAISON, 2009)

A Fécula de mandioca é o produto amiláceo extraído da mandioca, seu processo produtivo genericamente apresenta estas etapas: lavagem e descascamento das raízes, ralação, prensagem, para separação do leite de amido, esfarelamento da massa, peneiramento, torração, peneiramento (opcional), acondicionamento, e armazenagem (MATSURA et al., 2003).

Em fecularias os efluentes são provenientes da lavagem, descascamento das raízes de mandioca, da separação do amido nas centrífugas e da passagem por filtros a vácuo. A água de lavagem e descascamento representa um volume de 3 a $6 \mathrm{~m}^{3} \mathrm{t}^{-1} \mathrm{de}$ raiz (PINTO, 2013). Quando estas águas são 
eliminadas de forma inapropriada podem contaminar rios, lençóis freáticos e causar a morte de animais aquáticos. A toxidez para peixes foi estimada em $0,025 \mathrm{mg} \mathrm{L}^{-1}$, sendo que o limite estabelecido em água para consumo por seres humanos é de $0,01 \mathrm{mg} \mathrm{L}^{-1}$, expresso em $\mathrm{CN}^{-}$(FIORETTO, 2001).

\subsection{Coagulação/Floculação}

Os coagulantes/floculantes naturais têm demonstrado vantagens em relação aos químicos, especificamente em relação à biodegradabilidade, baixa toxicidade e baixo índice de produção de lodos residuais (MORAES, 2004).

Sendo a fase de coagulação definida como a de mistura rápida para que ocorra a distribuição uniforme do coagulante e todas as partículas tenham contato como o mesmo. A fase de mistura lenta ou floculação é onde acontece a aglutinação de partículas ou flocos, que aumentam de tamanho tornando-se sedimentáveis.

Assim, este trabalho teve como objetivo estudar o tratamento do efluente da indústria de produção de fécula de mandioca utilizando o processo de coagulação/ floculação. A curva de sedimentação do coagulante natural foi obtida para seleção do tempo mínimo de sedimentação e comparada sua eficiência ao de um coagulante químico convencional.

\section{MATERIAS E METODOS}

O efluente empregado neste estudo foi gentilmente cedido por uma indústria processadora de mandioca, localizada no oeste do Estado do Paraná. As coletas foram realizadas de acordo com o guia nacional de coletas e preservação de amostras das agências CETESB/ANA (2011).

As análises para caracterização do efluente foram realizadas em triplicata conforme metodologias do Standard Methods for the Examination of Water and Wastewater (APHA, 1998), sendo os parâmetros analisados descritos na Tabela 1.

Tabela 1 - Metodologia e parâmetros físicoquímicos utilizados na caracterização do efluente

\begin{tabular}{|c|c|c|}
\hline Parâmetro & Método & Equipamento \\
\hline $\begin{array}{l}\text { Cor } \\
\text { aparente }\end{array}$ & Colorimétrico & $\begin{array}{l}\text { Espectrofotômetro } \\
\text { (Modelo Hitachi } \\
\text { U-1800) }\end{array}$ \\
\hline DQO & $\begin{array}{l}\text { Colorimétrico } \\
\text { em refluxo } \\
\text { fechado }\end{array}$ & $\begin{array}{l}\text { Espectrofotômetro } \\
\text { (Modelo Hitachi } \\
\text { U-1800) }\end{array}$ \\
\hline Íon cianeto & Colorimétrico & $\begin{array}{l}\text { Espectrofotômetro } \\
\text { (Modelo Hitachi } \\
\text { U-1800) }\end{array}$ \\
\hline $\mathrm{pH}$ & Potenciométrico & $\begin{array}{l}\text { Phmetro Digimed } \\
\text { (Modelo DM-22) }\end{array}$ \\
\hline $\begin{array}{l}\text { Sólidos } \\
\text { Totais }\end{array}$ & Gravimétrico & \\
\hline Turbidez & Nefelométrico & $\begin{array}{l}\text { Turbidímetro } \\
\text { (Modelo Hach } \\
\text { 2100P) }\end{array}$ \\
\hline
\end{tabular}

Nos ensaios de coagulação/floculação foram avaliados dois tipos de coagulantes, um orgânico e um inorgânico. $O$ coagulante natural Acquapol WW, de caráter catiônico, extraído da casca da Acacia mearnsii (Acacianegra) foi fornecido pela empresa SETA S.A. (Estância Velha, RS). O coagulante químico empregado foi $\mathrm{o}$ sulfato de alumínio $\left(\mathrm{Al}_{2}\left(\mathrm{SO}_{4}\right)_{3} \cdot(14-18) \mathrm{H}_{2} \mathrm{O}\right)$ q.p. da marca Cinética Química .

A solução padrão de coagulante natural foi preparada diluindo-se $5 \mathrm{~mL}$ do Acquapol WW e completando o volume de água destilada para $50 \mathrm{~mL}$. A solução padrão do coagulante químico foi preparada a partir do sulfato de alumínio em pó, dissolvendo-se $2 \mathrm{~g}$ de sulfato de alumínio em água destilada e completando o volume para $50 \mathrm{~mL}$.

Os ensaios de coagulação/ floculação foram realizados no equipamento Jar Test 
(modelo JT102-Milan), empregando-se em cada cuba um volume de 0,5 litros de amostra do efluente.

Para avaliar a eficiência de cada coagulante (Acquapol, sulfato de alumínio) no tratamento do efluente em relação a sua dosagem e o tempo de sedimentação dos flocos foram utilizadas cinco concentrações da solução dos coagulantes, conforme apresentadas na Tabela 2 .

Tabela 2 - Concentrações utilizadas para triagem dos coagulantes

\begin{tabular}{cccccc}
\hline Coagulante & \multicolumn{4}{c}{$\begin{array}{c}\text { Concentração } \\
\left(\mathrm{mg} \mathrm{L}^{-1}\right)\end{array}$} \\
\hline Acquapol WW & 15 & 30 & 45 & 60 & 75 \\
Sulfato alumínio & 15 & 30 & 45 & 60 & 75 \\
Fonte: Autor (2015). & & & & &
\end{tabular}

As condições de operação dos ensaios de coagulação/floculação foram estabelecidas em uma mistura rápida de $120 \mathrm{rpm}$ durante 2 minutos e seguido de mistura lenta de $20 \mathrm{rpm}$ por 15 min. Durante a sedimentação dos flocos, amostras de sobrenadante $(60 \mathrm{~mL}$ do efluente tratado) foram retiradas a cada 5 minutos até completar 20 minutos de experimento.

Para avaliar a eficiência da coagulação/floculação foram analisados os parâmetros pH, cor aparente (unid. Pt-Co) e turbidez (NTU). Experimentos sem adição de coagulante na amostra de efluente foram conduzidos simultaneamente como controle (branco). Todos os experimentos foram realizados sem correção do $\mathrm{pH}$ do efluente em temperatura ambiente e em duplicata.

\section{RESULTADOS E DISCUSSÃO}

$\mathrm{Na}$ indústria processadora da mandioca são gerados $40 \mathrm{~m}^{3} / \mathrm{h}$ de efluente, provindo da água de lavagem das raízes e da extração da fécula.
Na Tabela 3 são apresentados os resultados da caracterização do efluente da indústria de processamento da mandioca.

Tabela 3 - Caracterização da água residuária da fecularia

\begin{tabular}{|c|c|c|c|}
\hline Parâmetro & Resultados & Un. & $\begin{array}{r}\text { CONAMA } \\
430 / 2011\end{array}$ \\
\hline $\mathrm{pH}$ & 6,7 & & 5 a 9 \\
\hline $\begin{array}{l}\text { Cor } \\
\text { aparente }\end{array}$ & 11.675 & $\begin{array}{l}\text { (unid. } \\
\text { Pt-Co) }\end{array}$ & - \\
\hline DQO & $7.731,7$ & $\begin{array}{l}\mathrm{mg} \mathrm{O}_{2} \\
\mathrm{~L}^{-1}\end{array}$ & - \\
\hline $\begin{array}{l}\text { Ílon cianeto } \\
\text { (livre) }\end{array}$ & 1,3 & $\mathrm{mg} \mathrm{L}^{-1}$ & $\begin{array}{l}0,2 \\
\mathrm{mg}^{2} \\
\mathrm{~L}^{-1}\end{array}$ \\
\hline $\begin{array}{l}\text { Sólidos } \\
\text { totais }\end{array}$ & $6.286,3$ & $\mathrm{mg} \mathrm{L}^{-1}$ & - \\
\hline Turbidez & $2.939,0$ & NTU & - \\
\hline
\end{tabular}

Observa-se que o valor do parâmetro DQO (7.731,7 $\left.\mathrm{mg} \mathrm{O}_{2} \mathrm{~L}^{-1}\right)$ está muito acima do permitido pela Resolução do Conselho Estadual de Meio Ambiente (CEMA/IAP) do estado do Paraná 070/2009 (350 mg O $\mathrm{L}^{-1}$ ), demonstrando que a manipueira resultante do processo de industrialização da mandioca possui alta carga orgânica.

Nos trabalhos de CEREDA (1996) e PONTELLO (2005) a água de despejo de fecularia também foi alta, apresentando DQO de 6.000 e $9.285 \mathrm{mg} \mathrm{O}_{2} \mathrm{~L}^{-1}$, respectivamente. $\mathrm{O}$ íon cianeto $\left(1,3 \mathrm{mg} \mathrm{L}^{-1}\right)$ apresentou um valor superior ao permitido pela CONAMA na Resolução 430/2011 que apresenta limite máximo para cianeto livre de $0,2 \mathrm{mg} \mathrm{L}^{-1}$, o que requer tambem adequado tratamento.

A turbidez (2.939,0 NTU) do efluente industrial está associada à quantidade elevada de sólidos totais $\left(6.286,3 \mathrm{mg} \mathrm{L}^{-1}\right)$ presente no efluente, valor este próximo ao obtido por LIMONS (2008) de $6.000 \mathrm{mg} \mathrm{L}^{-1}$ para o mesmo tipo de efluente. O parâmetro cor (11.675 unid. Pt-Co) apresentou valor elevado, o que também foi constatado em 
efluente de fecularia por LIED (2012) com 5.270 unid. Pt-Co .

Os sólidos totais correspondem ao material particulado de resíduos de mandioca e terra aderida as raízes que se originam durante a lavagem e higienização da mandioca.

De maneira geral, os altos valores obtidos para os parâmetros analisados na caracterização do efluente mostram a necessidade de um adequado tratamento deste resíduo líquido de modo a atender os limites de lançamento estabelecidos pela legislação vigente.

\subsection{Análise da Curva de Sedimentação}

Ensaios de coagulação/floculação foram realizados para o coagulante natural Acquapol WW. Na Figura 1 e 2 são apresentadas as curvas de sedimentação obtidas para diferentes dosagens do coagulante Acquapol avaliando-se os parâmetros cor e turbidez durante 20 minutos.

Figura 1 - Curva de sedimentação para o coagulante natural Acquapol WW

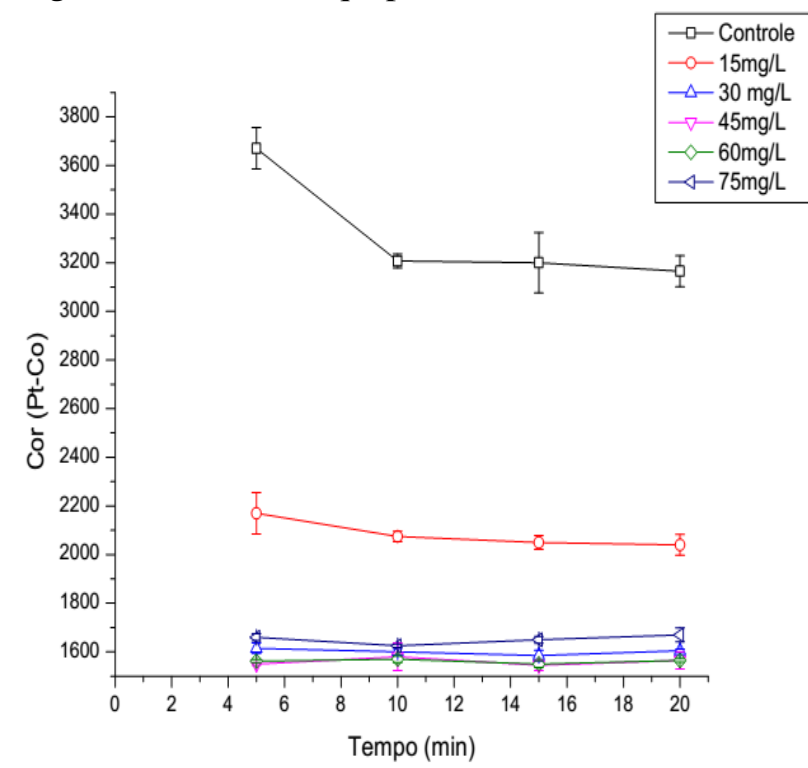

Fonte: Autor (2015).
Figura 2 - Curva de sedimentação para o coagulante natural Acquapol WW

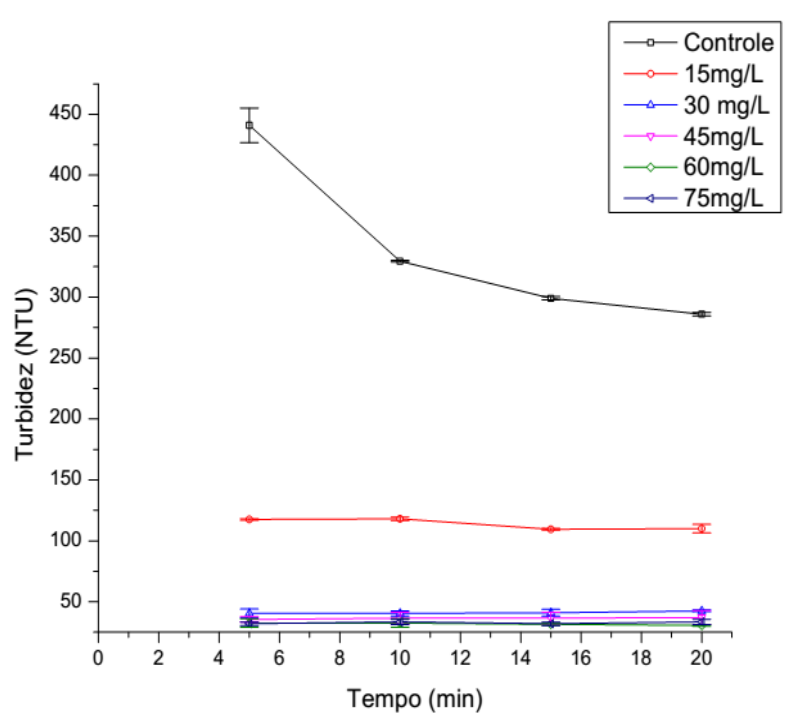

Fonte: Autor (2015).

A remoção de turbidez foi de 40 NTU para a concentração de $30 \mathrm{mg} \mathrm{L}^{-1}$ de coagulante e de 32 NTU para a de $75 \mathrm{mg} \mathrm{L}^{-1}$. Para a cor nas mesmas concentrações obtevese 2075 unid. Pt-Co $\left(30 \mathrm{mg} \mathrm{L}^{-1}\right)$ e 1625 unid. Pt-Co $\left(75 \mathrm{mg} \mathrm{L}^{-1}\right)$, respectivamente.

Esses resultados indicam não ser vantajoso economicamente o uso de grandes concentrações de coagulante pois pode-se obter uma boa eficiência de remoção utilizando a menor concentração de $30 \mathrm{mg} \mathrm{L}^{-}$ 1 .

Os valores de turbidez e cor apresentam uma rápida redução nos primeiros cinco minutos estabilizando em 10 minutos.

$\mathrm{O}$ parâmetro $\mathrm{pH}$ foi analisado nos diferentes tempos de coleta do efluente tratado e seus valores se mantiveram praticamente constante em relação ao controle $(3,85)$, demonstrando que o coagulante Acquapol WW não altera o pH do meio.

$\mathrm{Na}$ Figura 3 e 4 são apresentadas as porcentagens de remoção de cor e turbidez do efluente utilizando o coagulante natural e o convencional sulfato de alumínio para um tempo de sedimentação de 10 minutos. 
Figura 3 - Remoção de cor e turbidez pelo coagulante Acquapol WW

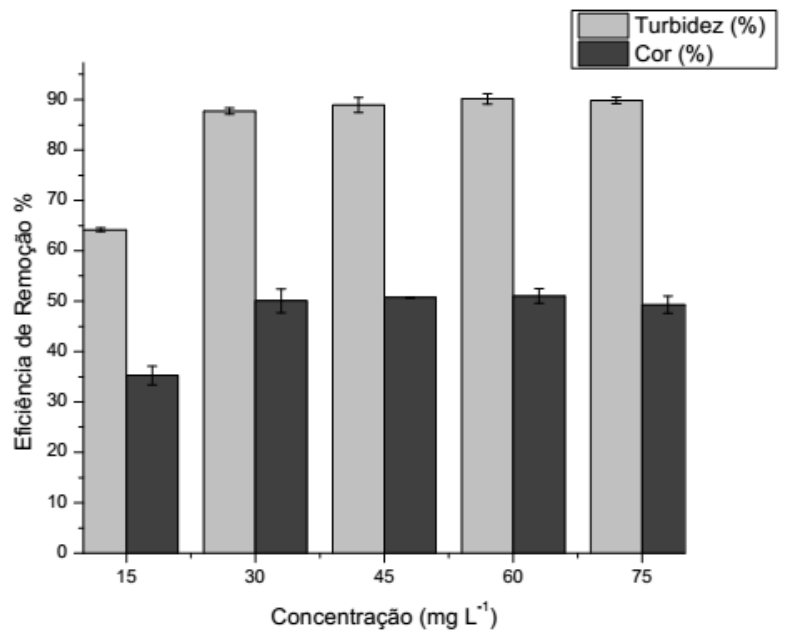

Com o coagulante natural a base de tanino obteve-se valores de eficiência muito superiores quando comparado ao sulfato de alumínio, até mesmo em concentrações menores (Figura 4). Para o coagulante natural, a maior variação na remoção da cor e turbidez pode ser observada na concentração de 15 para $30 \mathrm{mg} \mathrm{L}^{-1}$. Para as maiores concentrações uma diferença adicional em torno de $1 \%$ e de $2,4 \%$ ocorre para os parâmetros cor e turbidez, respectivamente.

Figura 4 - Remoção de cor e turbidez pelo coagulante Sulfato de Alumínio

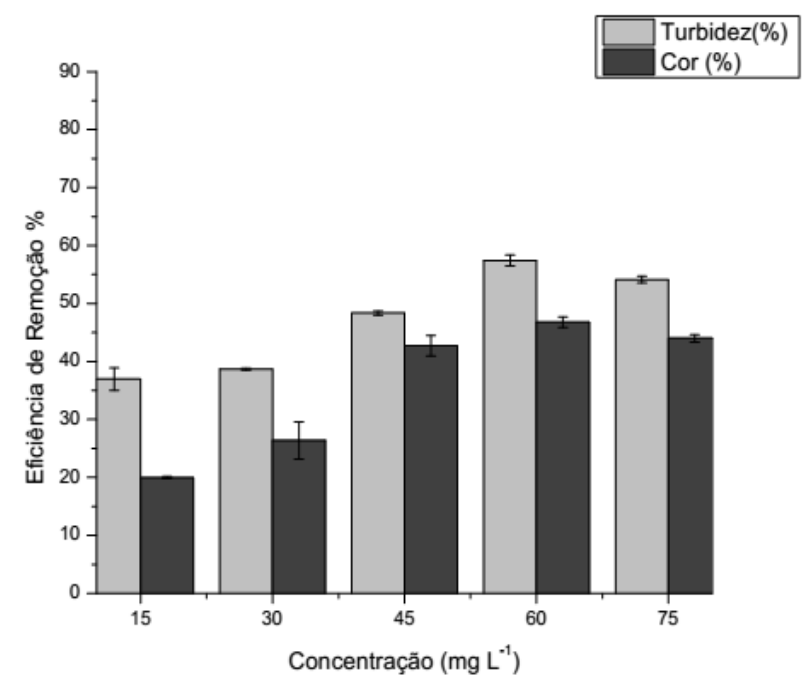

$\mathrm{Na}$ Figura 4 observou-se maior variação de remoção na concentração de 30 a $60 \mathrm{mg} \mathrm{L}^{-1}$ onde houve aumento da remoção da cor de $16,39 \%$ para $46,78 \%$, e turbidez de $38,71 \%$ para $57,42 \%$, para o coagulante inorgânico.

\section{CONSIDERAÇOES FINAIS}

Nos ensaios realizados, a curva de sedimentação com Acquapol WW obteve um tempo mínimo de sedimentação igual a 10 min. Ao comparar-se a eficiência de remoção do agente coagulante natural a base de tanino e do sulfato de alumínio, verificou-se que o natural apresentou uma eficiência de remoção muito superior ao sulfato de alumínio.

$\mathrm{O}$ tratamento do efluente de fecularia por coagulação/floculação apresentou bons resultados, sendo um método físico-químico eficaz para $o$ tratamento deste tipo de efluente.

Apesar de eficiente como um prétratamento para remoção de cor e turbidez, para que seja alcançado os padrões de lançamento se faz necessário a aplicação de outros tratamentos posteriores.

\section{NOMENCLATURA}

DQO: Demanda química de Oxigênio $\mathrm{mg} \mathrm{L}^{-1}$ : miligrama por Litro NTU: Nephelometric Turbidity Unit Un. Pt-Co: Unidade de Platina Cobalto

\section{REFERÊNCIAS}

BRSCAN, I. M. 2011. Manipueira, um líquido preso. Embrapa Disponível em $:<$ http://www.embrapa.br/imprensa/noticias/2 011/junho/2a-semana/manipueira-um-liquidoprecioso>. Acesso em: 20 dez. 2014.

CETESB - Companhia de Tecnologia de Saneamento Ambiental. Variáveis de qualidade das águas. Disponível em: 
<http://www.cetesb.sp.gov.br/agua/\%C3\%81 guas-Superficiais/34-Vari\%C3\%A1veis-deQualidade-das-\%C3\%81guas\#carbono_total>. Acesso em: 20 set. 2014.

CEREDA, M. P. Caracterização dos Subprodutos da Industrialização da Mandioca. In: CEREDA, M.P. Manejo, Uso e Tratamento de Subprodutos da Industrialização da Mandioca. São Paulo: Fundação Cargill, v.4, 2001.

FIORETTO, R.A., Uso direto da manipueira em fertirrigação. In: CEREDA, M. P (coord): Manejo, Uso e Tratamento de Subprodutos da Industrialização da Mandioca. v. 4. São Paulo: Fundação CARGILL, 2001. p. 67-79.

LIED, E. Borges. Tratamento de efluente industrial de fecularia utilizando Macrófita aquática eichhornia crassipes e coagulante natural. Dissertação (Mestrado) Universidade Estadual do Oeste do Paraná. Programa de Pós Graduação Stricto sensu em Engenharia Química. Toledo, 2012.

LIMONS, R. da S. Avaliação do Potencial de Utilização da Mácrofita Aquática Seca Salvinia SP. no tratamento de efluentes de fecularia. Toledo, 2008, 101p. Dissertação (Mestrado em Engenharia Química).

LAMAISON, F. do C. Aplicação da água residuária do processamento da mandioca como substrato para a produção de hidrogênio por processo fermentativo. Dissertação (Mestrado Engenharia de Alimentos) - Universidade Federal de Santa Catarina, Florianópolis - SC 2009

MATSURA, F.do C.A.U., FOLEGATTI, M. I.S.; SARMENTO, S. B.S. Iniciando um pequeno negócio agroindustrial: processamento da mandioca. Brasília:
Embrapa mandioca e fruticultura/SEBRAE, 2003. 115p. (série agronegócios)

MORAES, L.C.K. Estudo da coagulaçãoultrafiltração com o biopolímeroquitosana para a produção de água potável. 2004. Dissertação (Mestrado em Engenharia Química) - Universidade Estadual de Maringá, Maringá, 2004.

PINTO, P. H. Mendonça. Tratamento de manipueira de fecularia utilizando processos oxidativos com peróxido de hidrogênio, Ozônio e radiação ultravioleta. Tese (Doutorado) Faculdade de Ciências Agronômicas da Unesp. Programa de Pós Graduação Stricto sensu em Agronomia. Botucatu, 2013.

PONTELlO, C. J. Efeito da Cobertura plástica no desempenho de uma lagoa anaeróbia tratando efluente de indústria de fécula de mandioca. Cascavel, 2005, 69p. Dissertação (Mestrado em Engenharia Agrícola). Universidade Estadual do Oeste do Paraná (UNIOESTE), Campus de Cascavel, PR.

Standard Methods for the Examination of Water and Wastewater, 20th ed., American Public Health Association: Washington, 1998.

\section{AGRADECIMENTOS}

Agradecimento a Capes pelo apoio financeiro e as indústrias que gentilmente cederam o efluente e coagulante. 